\title{
Effect of Cooking on Total Antioxidant Activity, Polyphenols and Flavanoid Content in Commonly Consumed Vegetables
}

\author{
K. Geetha*, Savita Hulamani and H.B. Shivaleela
}

AICRP-Home Science (Foods and Nutrition), University of Agricultural sciences, GKVK, Bengaluru-65, Karnataka, India

*Corresponding author

\section{A B S T R A C T}

In India, most of the vegetables are processed before consumption and are cooked by boiling in water or roasting or deep-frying or microwaving. These cooking processes would bring about a number of changes in physical characteristics and chemical composition of vegetables. Thus, the present study helps to know the effect of different

Keywords

Vegetables,

Processing methods,

Antioxidant activity,

Flavanoid content,

Polyphenolic content, analysis

Article Info

Accepted:

15 January 2018

Available Online:

10 February 2018 commonly used household processing methods on total antioxidant activity, flavanoid content and total polyphenols content of the selected vegetables. A total of six green leafy vegetables and five other vegetables namely red amaranthus, fenugreek, curry leaves, drumstick leaves, shepu, cabbage, ridge gourd, tomato, small brinjal, cluster bean and French bean were selected for the study. Vegetables were sorted, cleaned and edible portion of vegetables were cut into uniform size of one-centimeter cube using vegetable chopper except green leafy vegetables. The green leafy vegetables were also chopped into uniform pieces with knife as used at household level. The total polyphenolic content, flavanoid content and total antioxidant activity were analyzed in raw and vegetable cooked by two different household processing methods namely open boiling and pressure-cooking. It is a concluded that unprocessed or raw foods is healthier, especially vegetables but still cooking vegetables before consumption is a most widely practiced in India. It is important to know the best method of cooking to retain the health beneficial constituents in the vegetables. The present study indicates that pressure cooking in phenolics and flavanoids better to enhance the total antioxidant activity in Green leafy vegetables and other vegetables.

\section{Introduction}

Fruits and vegetables account for a small part of our daily caloric intake; however their benefits to health surpass their caloric contribution. The contributory factors are due to the presence of vitamins and provitamins, such as ascorbic acid, tocopherols and carotenoids and, in addition to that, they are also rich in a wide variety of phenolic substances (Loliger, 1991). Phenolic substances are a category of phytonutrients that exert strong antioxidant properties (Ho, 1992). They can be classified into simple phenols, phenolic acids, hydroxycinnamic acid derivatives and flavonoids. The ability of some of the phenolic substances to act as potent antioxidant components has been 
reported (Velioglu et al., 1998; K€ahkonen et al., $€$ 1999). The principle function of antioxidants is in delaying the oxidation of other molecules by inhibiting the initiation or propagation of oxidizing chain reactions by free radicals and they may reduce oxidative damage to the human body (Namiki, 1990).

Antioxidants are any substances that delay or inhibit oxidative damage to a target molecule by scavenging the free radicals. At a time one antioxidant molecule can react with single free radicals and are capable to neutralize free radicals by donating one of their own electrons, ending the carbon starting reaction. Antioxidants prevent cell and tissue damage as they act as scavenger. Cell produces defense against excessive free radicals by this preventive mechanisms, physical defenses and oxidant defenses (Jacob, 1995).

Free radicals are generally involved in chain reactions, which is series of reactions leading to regenerate a radical that can begin a new cycle of reactions. The occurrence of such oxidative damage may be a significant causative factor in the development of many chronic diseases, such as cancer and cardiovascular diseases (Lindley, 1998; Papas, 1999). Several epidemiological studies have shown a negative association between intake of fruits and vegetables and certain diseases (Papas, 1999). Cao et al., (1996) found that vegetables, such as kale, beets, pepper, broccoli, spinach, shallots, potato, carrots and cabbage, had high antioxidant activities. Kale, spinach, swamp cabbage, cabbage and shallots are some of the commonly consumed vegetables in Malaysia. Beside antioxidant nutrients such as ascorbic acid, tocopherols, and carotenoids, these vegetables are also a good source of polyphenol components. Vegetables are generally consumed in the cooked form than raw. Cooking may affect the antioxidant content in vegetables, especially components such as tocopherol, carotenoids, ascorbic acid and polyphenols. In recent years, increasing attention has been paid by consumer, food industry and researcher to the role of diet and food in health promotion and diseases prevention. Epidemiological studies have shown that a high intake of plant originated food is strongly associated with a reduced risk of a number of chronic diseases, as well as inflammation, problems caused by free radicals, cutaneous aging (Das gupta and Be, 2007), cataract, muscular degeneration (Turkmen et al., 2005) and diabetes (cai et al., 2004). Number of studies have also shown that diet rich in fruits and vegetables are protective against diseases and population that consume such diets have the higher plasma antioxidants states and exhibit lower risk of chronic degenerative diseases (Azizah et al., 2009; Chipurura et al., 2010; Adefegha and Oboh, 2011).

Recent reports suggest that vegetables act as a good source of natural antioxidants due to the high levels of carotenoids, tocopherols and ascorbic acid. In addition to carotenoids, tocopherols and ascorbic acid, most of the anti-oxidative effect related to plant food intake is mainly due to the presence of phenolic compounds which have been associated with flavor and color characteristics of vegetables. The majority of the antioxidant of a fruit or vegetables may be from polyphenolic compounds rather than from vitamin C, E or $\beta$-carotene (Wang et al., 1996; Kahkonen et al., 1999)

In India most of the vegetables are processed before consumption and are cooked by boiling in water or roasting or deep frying or microwaving. These cooking processes would bring about a number of changes in physical characteristics and chemical composition of vegetables (Rahman et al., 2003; Zhang and Hamauzu, 2004). Many studies have showed that the nutritional value of fresh fruits and vegetables are higher than those of processed 
one. Thus the present study helps to know the effect of different commonly used household processing methods on total antioxidant activity, Flavanoid content and total polyphenols content of the selected vegetables.

\section{Materials and Methods}

\section{Selection and procurement of vegetables}

A total of six green leafy vegetables and five other vegetables namely red amaranthus, Fenugreek, Curry leaves, Drumstick leaves, shepu, Cabbage, Ridge gourd, Tomato, Small Brinjal, Cluster bean and French bean were selected for the study. All selected vegetables were purchased fresh from local market, cleaned and edible portions were used for the analysis. Bioactive compounds were extracted on the same day.

\section{Household processing of vegetables}

Vegetables were sorted, cleaned and edible portion of vegetables were cut into uniform size of one centimeter cube using vegetable chopper except green leafy vegetables. The green leafy vegetables were also chopped into uniform pieces with knife as used at household level. The total polyphenolic content, flavanoid and total antioxidant activity were analyzed in raw and vegetable cooked by two different household processing methods namely open boiling and pressure cooking.

\section{Open boiling}

The selected vegetables were boiled in a stainless steel vessel till cooked. The vegetable to water ratio was $1: 10$. The samples were drained on stainless steel sieve until cold and then used for extraction and analysis of total polyphenolic content, flavanoid and total antioxidant activity.

\section{Pressure cooking}

Vegetable sample were cooked in domestic pressure cooker of one litre capacity, care was taken to avoid water entering into the sample container by placing the weighed sample in a container covered with an aluminum foil. The samples were drained on stainless steel sieve until cold and then used for extraction and analysis.

\section{Extraction of bioactive compounds}

Raw as well as cooked samples, $2-5 \mathrm{~g}$ were weighed, grounded manually using pestle and mortar by adding $10 \mathrm{ml}$ acidified 80 percent methanol. The ground aliquot was collected in $50 \mathrm{ml}$ propylene centrifuge tube with cap. $10 \mathrm{ml}$ of acidified methanol was again added to pestle and mortar, washing thoroughly to ensure no residue is left in pestle and mortar, and then transferred to the centrifuge tube.

Propylene centrifuge tube containing sample extract was kept for 30 minutes on mechanical shaker at room temperature. After 30 minutes, the extract was centrifuged at $10,000 \mathrm{rpm}$ for 10 minutes and supernatant was collected in $100 \mathrm{ml}$ conical flask. $10 \mathrm{ml}$ of acidified 80 per cent methanol was added again into the same centrifuge tube containing remaining residues and kept shaking for 30 minutes, centrifuged for 10 minutes and then the supernatant was collected in the same conical flask. The process was repeated three times to ensure that all bioactive compounds were extracted completely. The conical flask containing all three aliquots was filtered with whatman no.1 filter paper into $50 \mathrm{ml}$ volumetric flask and volume was made up to $50 \mathrm{ml}$ with 80 per cent acidified methanol. Then the filtered extract was transferred into $60 \mathrm{ml}$ sterile propylene bottles and stored at $-20^{\circ} \mathrm{c}$ and used for estimation of total polyphenolic content, flavanoid and total antioxidant activity. 


\section{Estimation of Total Polyphenolic Content (TPC)}

The total polyphenolic content of the extract was determined using the method reported by Singleton et al., (1999)

\section{Calculation of Total Polyphenolic Content (TPC)}

$$
\operatorname{TPC}(\mathrm{mg} \text { GAE } / 100 \mathrm{gm})=\frac{\text { Std. Conc Sample 0.D Volume make up } 100}{\mathrm{Std} .0 .0 \text { Aliquot taken weight of sample } 1000}
$$

Total polyphenolic content was expressed as milligram of Gallic acid equivalent per $100 \mathrm{~g}$ of sample (mg GAE/100g)

\section{Estimation of Total Antioxidant Activity (TAA)}

The total antioxidant activity (TAA) of the extract was determined using the 2,2Diphenyl-1-picrylhydrazyl (DPPH) method reported by Brand-William et al., (1995.)

Calculation of \% DPPH inhibition

$\%$ Inhibition $=\frac{(\text { Ac-Ae })}{\text { Ac }}$

(Where, Ac is absorbance of control and Ae is absorbance of sample extract)

\section{Calculation of Total Antioxidant Activity} (TAA)

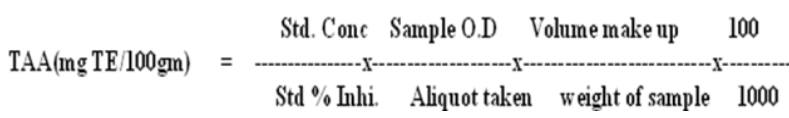

\section{Estimation of Flavanoids (TF)}

The flavanoid content (FC) of the exctract was determined using Rutin method reported by Zhishen et al., (1999)
Calculation of Flavanoids

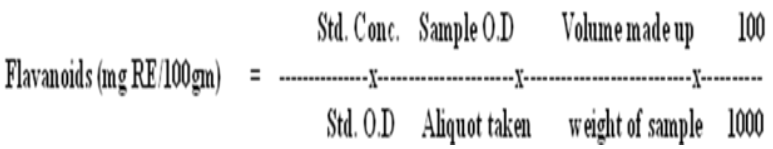

\section{Results and Discussion}

\section{Total Antioxidant Activity (TAA)}

Among the green leafy vegetables analyzed in raw farm, curry leaves had higher content of total antioxidant of $2.84 \mathrm{mg} \mathrm{TE} / \mathrm{gm}$, followed by cabbage (2.56 $\mathrm{mg}$ TE/gm), red amaranthus (2.32 mg TE/gm), Shepu (1.76 mg TE/gm) Fenugreek (1.61 mg TE/gm) and drumstick leaves $(0.64 \mathrm{mg}$ TE/gm) per 100gm of sample analyzed.

Pressure cooking was found to increase the total antioxidant in fenugreek $(3.03 \mathrm{mg}$ TE/gm), drumstick (0.67 mg TE/gm) and cabbage leaves (2.95 mg TE/gm) but found to be decrease in red amaranthus (1.43 mg $\mathrm{TE} / \mathrm{gm})$, curry leaves $(0.73 \mathrm{mg} \mathrm{TE} / \mathrm{gm})$ and shepu (0.78 $\mu \mathrm{g}$ TE/gm). However, the reduction in total antioxidant was slightly lower in pressure-cooking than open cooking.

The difference TAO from raw to cooked and between the green leafy vegetables was found to be statistically significantly. Sreeramulu et al., (2013) and Jimenez-monreal et al., (2009) have reported similar findings in a study on antioxidant in raw and cooked green leafy vegetables.

Kenny and Obairna (2009) indicated that loss of antioxidants activity was relating to the contact area between vegetables and as well as processing time, longer the cooking time, more is loss. Further during open cooking, leaching of antioxidants with the boiling media results in the decrease of TAA compared to pressure cooking. 
Table.1 Anti-oxidant scavenging activity $\left(\mathrm{mg} \mathrm{TE} 100 \mathrm{~g}^{-1}\right)$ in leafy vegitables measured by DPPH and FRAP method

\begin{tabular}{|c|c|c|c|c|c|c|}
\hline \multirow[t]{3}{*}{ Leafy vegetables } & \multicolumn{6}{|c|}{ Anti-oxidant scavenging activity } \\
\hline & \multicolumn{3}{|c|}{ DPPH Method $\left(m g\right.$ TE $\left.100 g^{-1}\right) \pm S E$} & \multicolumn{3}{|c|}{ FRAP Method $\left(\operatorname{mg}\right.$ TE $\left.100 g^{-1}\right) \pm S E$} \\
\hline & Raw & $\begin{array}{l}\text { Open cooking } \\
\text { (With husk) }\end{array}$ & $\begin{array}{l}\text { Pressure cooking } \\
\text { (Without husk) }\end{array}$ & Raw & $\begin{array}{l}\text { Open cooking } \\
\text { (With husk) }\end{array}$ & $\begin{array}{l}\text { Pressure cooking } \\
\text { (Without husk) }\end{array}$ \\
\hline Red amaranthus (Amaranthus cruentus) & $2.32 \pm 0.07^{\mathrm{d}}$ & $1.76 \pm 0.01^{\mathrm{e}}$ & $1.43 \pm 0.06^{\mathrm{f}}$ & $39.28 \pm 3.20^{\mathrm{g}}$ & $38.18 \pm 0.92^{\mathrm{g}}$ & $36.64 \pm 0.35^{\mathrm{g}}$ \\
\hline Fenugreek (Trigonella foenum-graicum) & $1.61 \pm 0.13^{\mathrm{ef}}$ & $2.50 \pm 0.12^{\mathrm{cd}}$ & $3.03 \pm 0.04^{\mathrm{a}}$ & $28.61 \pm 2.03^{h}$ & $25.06 \pm 1.2^{\mathrm{h}}$ & $9.91 \pm 0.18^{\mathrm{ij}}$ \\
\hline Curry leaves (Murraya koenijii) & $2.84 \pm 0.01^{\mathrm{ab}}$ & $0.70 \pm 0.01^{\mathrm{g}}$ & $0.73 \pm 0.02^{\mathrm{g}}$ & $152.21 \pm 0.38^{\mathrm{a}}$ & $122.73 \pm 1.89^{\mathrm{d}}$ & $128.02 \pm 2.18^{c}$ \\
\hline Drum stick leaves (Moringa oleifera) & $0.64 \pm 0.01^{\mathrm{g}}$ & $0.64 \pm 0.04^{\mathrm{g}}$ & $0.67 \pm 0.04^{\mathrm{g}}$ & $150.65 \pm 2.29^{\mathrm{a}}$ & $121.25 \pm 1.51^{\mathrm{d}}$ & $135.19 \pm 0.28^{b}$ \\
\hline Shepu (Anethum graveolens) & $1.76 \pm 0.10^{\mathrm{e}}$ & $0.57 \pm 0.01^{\mathrm{g}}$ & $0.78 \pm 0.03^{\mathrm{g}}$ & $50.39 \pm 1.33^{\mathrm{ef}}$ & $52.66 \pm 1.64^{\mathrm{ef}}$ & $54.84 \pm 1.93^{\mathrm{e}}$ \\
\hline Cabbage (Brassica oleracea var-capitata) & $2.56 \pm 0.04^{c}$ & $2.79 \pm 0.03^{\mathrm{b}}$ & $2.95 \pm 0.11^{\mathrm{ab}}$ & $5.61 \pm 0.42^{j}$ & $14.33 \pm 0.72^{\mathrm{i}}$ & $12.17 \pm 1.28^{\mathrm{i}}$ \\
\hline LSD@ 0.05 & \multicolumn{3}{|l|}{0.18} & \multicolumn{3}{|l|}{4.40} \\
\hline $\mathrm{CV} \%$ & \multicolumn{3}{|l|}{6.52} & \multicolumn{3}{|l|}{4.56} \\
\hline
\end{tabular}

Table.2 Total flavonoids (mg RE $100 \mathrm{~g}^{-1}$ ) and Total phenols (mg GAE $100 \mathrm{~g}^{-1}$ ) content in leafy vegetables

\begin{tabular}{l}
\multicolumn{1}{c}{ Leafy vegetables } \\
\hline Red amaranthus (Amaranthus cruentus) \\
\hline Fenugreek (Trigonella foenum-graicum) \\
\hline Curry leaves (Murraya koenijii) \\
\hline Drum stick leaves (Moringa oleifera) \\
\hline Shepu (Anethum graveolens) \\
\hline Cabbage (Brassica oleracea var-capitata) \\
\hline LSD @ 0.05 \\
\hline CV\% \\
\hline
\end{tabular}

\begin{tabular}{|c|c|c|c|c|c|}
\hline \multicolumn{3}{|c|}{ Total flavonoids (mg RE $\left.100 \mathrm{~g}^{-1}\right) \pm \mathrm{SE}$} & \multicolumn{3}{|c|}{ Total phenols (mg GAE $\left.100 \mathrm{~g}^{-1}\right) \pm \mathrm{SE}$} \\
\hline Raw & $\begin{array}{l}\text { Open cooking } \\
\text { (With husk) }\end{array}$ & $\begin{array}{l}\text { Pressure cooking } \\
\text { (Without husk) }\end{array}$ & Raw & $\begin{array}{l}\text { Open cooking } \\
\text { (With husk) }\end{array}$ & $\begin{array}{c}\text { Pressure cooking } \\
\text { (Without husk) }\end{array}$ \\
\hline $559.85 \pm 10.03^{\mathrm{e}}$ & $338.15 \pm 25.70^{\mathrm{g}}$ & $618.20 \pm 7.78^{\mathrm{d}}$ & $129.47 \pm 3.84_{i}$ & $94.34 \pm 3.00^{j}$ & $169.26 \pm 0.87^{\text {gh }}$ \\
\hline $173.01 \pm 1.0^{\mathrm{h}}$ & $165.90 \pm 4.87^{\mathrm{h}}$ & $137.75 \pm 0.50^{\mathrm{h}}$ & $87.44 \pm 0.66^{j}$ & $87.01 \pm 2.76^{j}$ & $35.88 \pm 0.23^{\mathrm{k}}$ \\
\hline $562.53 \pm 24.35^{\mathrm{e}}$ & $1020.33 \pm 25.66^{\mathrm{b}}$ & $1118.29 \pm 18.21^{\mathrm{a}}$ & $245.02 \pm 12.50^{f}$ & $492.09 \pm 9.17^{b}$ & $586.78 \pm 24.98^{\mathrm{a}}$ \\
\hline $989.75 \pm 39.19^{b}$ & $683.39 \pm 28.05^{\mathrm{c}}$ & $1039.29 \pm 4.18^{b}$ & $432.54 \pm 5.51^{\mathrm{c}}$ & $352.96 \pm 1.31^{\mathrm{e}}$ & $386.32 \pm 2.79^{d}$ \\
\hline $315.75 \pm 11.22^{\mathrm{g}}$ & $452.00 \pm 10.10^{f}$ & $526.32 \pm 5.00^{\mathrm{e}}$ & $135.94 \pm 6.60^{\mathrm{i}}$ & $184.40 \pm 4.72^{\mathrm{g}}$ & $158.88 \pm 0.37^{\mathrm{h}}$ \\
\hline $48.27 \pm 0.59^{\mathrm{i}}$ & $64.59 \pm 5.63^{\mathrm{i}}$ & $73.49 \pm 0.70^{\mathrm{i}}$ & $26.23 \pm 0.57^{\mathrm{k}}$ & $31.80 \pm 1.16^{\mathrm{k}}$ & $26.97 \pm 4.26^{\mathrm{k}}$ \\
\hline \multicolumn{3}{|c|}{48.07} & \multicolumn{3}{|c|}{21.62} \\
\hline \multicolumn{3}{|c|}{5.88} & \multicolumn{3}{|c|}{4.41} \\
\hline
\end{tabular}


Table.3 Anti-oxidant scavenging activity $\left(\mathrm{mg} \mathrm{TE} 100 \mathrm{~g}^{-1}\right)$ in other vegetables measured by DPPH and FRAP method

\begin{tabular}{l}
\multicolumn{1}{c}{ Other vegetables } \\
\hline \\
\hline Ridge gourd (Lufa acutangula) \\
\hline Tomato (Solanum lycopersicum) \\
\hline Small brinjal (Solanum melongena) \\
\hline Cluster bean (Cyamopsis \\
tetragonoloba) \\
\hline French bean (Phaseolus vulgaris) \\
\hline LSD @ 0.05 \\
\hline CV \%
\end{tabular}

\begin{tabular}{|c|c|c|c|c|c|}
\hline \multicolumn{6}{|c|}{ Anti-oxidant scavenging activity } \\
\hline \multicolumn{3}{|c|}{ DPPH Method $\left(\mathrm{mg}\right.$ TE $\left.100 \mathrm{~g}^{-1}\right) \pm \mathrm{SE}$} & \multicolumn{3}{|c|}{ FRAP Method $\left(\operatorname{mg}\right.$ TE $\left.100 \mathrm{~g}^{-1}\right) \pm \mathrm{SE}$} \\
\hline Raw & $\begin{array}{c}\text { Open } \\
\text { cooking } \\
\text { (With husk) }\end{array}$ & $\begin{array}{l}\text { Pressure cooking } \\
\text { (Without husk) }\end{array}$ & Raw & $\begin{array}{c}\text { Open cooking } \\
\text { (With husk) }\end{array}$ & $\begin{array}{c}\text { Pressure } \\
\text { cooking } \\
\text { (Without husk) }\end{array}$ \\
\hline $2.66 \pm 0.24^{\mathrm{bc}}$ & $3.15 \pm 0.05^{\mathrm{ab}}$ & $2.59 \pm 0.06_{\mathrm{bc}}$ & $7.22 \pm 1.03^{\mathrm{ef}}$ & $6.71 \pm 0.71^{\mathrm{ef}}$ & $4.05 \pm 0.83^{\mathrm{f}}$ \\
\hline $2.71 \pm 0.09^{\mathrm{bc}}$ & $2.42 \pm 0.09^{\mathrm{cd}}$ & $2.43 \pm 0.02^{\mathrm{cd}}$ & $8.30 \pm 0.78^{\mathrm{de}}$ & $10.76 \pm 0.98^{\mathrm{d}}$ & $7.75 \pm 0.70^{\mathrm{de}}$ \\
\hline $2.78 \pm 0.07^{\mathrm{bc}}$ & $2.17 \pm 0.06^{\mathrm{cd}}$ & $1.85 \pm 0.08^{\mathrm{d}}$ & $15.00 \pm 0.76^{\mathrm{c}}$ & $24.75 \pm 1.44^{\mathrm{b}}$ & $29.43 \pm 2.16^{\mathrm{a}}$ \\
\hline $3.73 \pm 0.02^{\mathrm{a}}$ & $2.56 \pm 0.05^{\mathrm{bc}}$ & $2.68 \pm 0.04^{\mathrm{bc}}$ & $16.16 \pm 1.12^{\mathrm{c}}$ & $16.66 \pm 0.35^{\mathrm{c}}$ & $16.63 \pm 1.03^{\mathrm{c}}$ \\
\hline $3.71 \pm 0.35^{\mathrm{a}}$ & $2.74 \pm 0.06^{\mathrm{bc}}$ & $1.80 \pm 0.65^{\mathrm{d}}$ & $7.94 \pm 1.24^{\mathrm{de}}$ & $9.93 \pm 0.21^{\mathrm{de}}$ & $6.94 \pm 0.03^{\mathrm{ef}}$ \\
\hline \multicolumn{3}{|c|}{0.59} & \multicolumn{3}{|c|}{3.11} \\
\hline \multicolumn{3}{|c|}{3.76} & \multicolumn{3}{|c|}{4.85} \\
\hline
\end{tabular}

Table.4 Total flavonoids (mg RE $100 \mathrm{~g}^{-1}$ ) and Total phenols (mg GAE $100 \mathrm{~g}^{-1}$ ) content in other vegetables

\begin{tabular}{|c|}
\hline Other vegetables \\
\hline Ridge gourd (Lufa acutangula) \\
\hline Tomato (Solanum lycopersicum) \\
\hline Small brinjal (Solanum melongena) \\
\hline $\begin{array}{l}\text { Cluster bean (Cyamopsis } \\
\text { tetragonoloba) }\end{array}$ \\
\hline French bean (Phaseolus vulgaris) \\
\hline LSD@0.05 \\
\hline $\mathrm{CV} \%$ \\
\hline
\end{tabular}

Total flavonoids (mg RE $\left.100 \mathrm{~g}^{-1}\right) \pm \mathrm{SE}$

\begin{tabular}{l|l|l|l} 
Raw & Open & Pressure cooking
\end{tabular}

cooking

(With husk)

\begin{tabular}{|r|r|c|}
\hline $80.74 \pm 1.98^{\text {ef }}$ & $90.40 \pm 9.73^{\mathrm{e}}$ & $55.19 \pm 2.97^{\mathrm{h}}$ \\
\hline $65.49 \pm 2.36^{\mathrm{gh}}$ & $70.23 \pm 3.61^{\mathrm{tg}}$ & $77.44 \pm 4.42^{\mathrm{tg}}$ \\
\hline $146.63 \pm 0.39^{\mathrm{c}}$ & $243.74 \pm 1.02^{\mathrm{b}}$ & $264.98 \pm 7.88^{\mathrm{a}}$ \\
\hline $118.39 \pm 1.54^{\mathrm{d}}$ & $115.31 \pm 1.79^{\mathrm{d}}$ & $141.79 \pm 3.33^{\mathrm{c}}$ \\
\hline $81.72 \pm 3.15^{\text {ef }}$ & $92.33 \pm 1.76^{\mathrm{e}}$ & $75.91 \pm 1.86^{\text {fg }}$ \\
\hline & $\mathbf{9 . 7 0}$ & \\
\hline & $\mathbf{4 . 0 7}$ & \\
\hline
\end{tabular}

Total phenols $\left(\mathrm{mg} \mathrm{GAE} 100 \mathrm{~g}^{-1}\right) \pm \mathrm{SE}$

\begin{tabular}{|c|c|c|}
\hline Raw & $\begin{array}{c}\text { Open cooking } \\
\text { (With husk) }\end{array}$ & $\begin{array}{c}\text { Pressure } \\
\text { cooking } \\
\text { (Without husk) }\end{array}$ \\
\hline $20.81 \pm 1.64^{\mathrm{gh}}$ & $24.11 \pm 1.23^{\mathrm{fg}}$ & $18.22 \pm 1.51^{\mathrm{h}}$ \\
\hline $19.58 \pm 0.70^{\mathrm{gh}}$ & $30.40 \pm 0.32^{\mathrm{e}}$ & $23.11 \pm 1.80^{\mathrm{tgh}}$ \\
\hline $56.22 \pm 1.21^{\mathrm{c}}$ & $101.13 \pm 3.88^{\mathrm{a}}$ & $103.82 \pm 1.48^{\mathrm{a}}$ \\
\hline $61.78 \pm 0.60^{\mathrm{b}}$ & $59.55 \pm 0.17^{\mathrm{bc}}$ & $61.57 \pm 0.22^{\mathrm{b}}$ \\
\hline $26.07 \pm 2.06^{\mathrm{ef}}$ & $37.94 \pm 2.08^{\mathrm{d}}$ & $29.19 \pm 1.77^{\mathrm{e}}$ \\
& $\mathbf{4 . 7 8}$ \\
& $\mathbf{3 . 3 9}$ \\
& &
\end{tabular}


Total antioxidants may increase or decrease due to cooking, because of maillard reaction. In some instances maillard reaction may reduce the total antioxidants after processing due to pro-oxidant activity of maillard reaction.

\section{Total polyphenols and flavanoids}

The total phenolic content was found to increase after cooking compared to raw form in most of the green leafy vegetables and other vegetables under study. Among the raw green leafy vegetables, drumstick leaves had highest phenolic content of $432.54 \mathrm{mg}$ GAE /100g) followed by curry leaves (245.02 mg GAE /100g), shepu (135.94 mg GAE /100g) red amaranthus (129.47 mg GAE /100g) fenugreek (87.44 mg GAE /100g) and cabbage (26.23 mg GAE /100g) respectively. Pressure cooking was found to increase the phenolic content in red amaranths (169.26 mg GAE /100g), drumstick leaves (386.32 mg GAE /100g), curry leaves (586.78 mg GAE /100g) whereas open cooking had increased phenolic content in fenugreek (87.01 mg GAE /100g), shepu(184.40 mg GAE $/ 100 \mathrm{~g}$ ) and cabbage(31.80 $\mathrm{mg}$ GAE /100g) among the other vegetables, pressure cooking had increased phenolic content in small brinjal (103.82 mg GAE /100g) and cluster bean (61.57 mg GAE /100g), whereas open cooking increased phenolic content in ridge gourd (24.11 mg GAE / $100 \mathrm{~g}$ ), tomato (30.40 mg GAE $/ 100 \mathrm{~g})$ and French bean (37.94 mg GAE /100g) in general cooking improved the phenolic content compared to raw, however, open cooking was better than pressure cooking to increase phenolic content.

The results are in tune with the findings reported on effect of cooking on phenolic content green leafy vegetables by sreeramulu 2013, other vegetables by Sasipriya (2012) and Sengul et al., (2014). The increase in polyphenols may be due to the release of phenolic compounds, which is the free or bound form in vegetables because of cooking.

Among the green vegetables cooked the total flavanoids was found to increase from raw form except in fenugreek leaves. The increase in flavanoids was more in pressure cooked samples Compared to open cooking.

The raw farm drumstick leaves had highest flevioneds (989-75 mg RE/100g) fold by curry leaves (562-53 mg RE/100g), red amaranths (560 mg RE/100g), shepu (315.75 mg RE/100g) fenugreek \& Cabbage (48.75 mg RE/100g).

Almost similar trend was observed for the other vegetables small brinjal had highest flavoniod content (146.63mg RE) fold by cluster bean (118.39 mg RE), French bean (81.72mg re), Ridge guard (80.74mg RE) \& Tomato $(65.49 \mathrm{mg}$ $\mathrm{RE}$ ) in raw form.

It is a common notion that unprocessed or raw foods is healthier, especially vegetables but still cooking vegetables before consumption is a most widely practiced in India. It is important to know the best method of cooking to retain the health beneficial constituents in the vegetables. The present study indicates that pressure cooking in phenolics and flavanoids better to enhance the total antioxidant activity in Green leafy vegetables and other vegetables.

\section{References}

Adefegha. S.A and Oboh. G. 2011. Cooking enhances the antioxidant properties of some tropical green leafy vegetables. Afr.J.Biotechnol, 10:632-639.

Azizah, A.H., Wee, K.C., Azizah, $\mathrm{O}$ and Azizah, M., 2009. Effect of boiling and stir frying on total phenolics, carotenoids and radical scavenging activity of pumpkin (Cucurbita moschato). Int.Food Res J., 16: 45:51

Cao, G., Sofic, E., \& Prior, R. L. (1996). Antioxidant capacity of tea and common vegetables. Journal Agricultural and Food Chemistry, 44, 3426-3431.

Chipurura, B., Muchuwei, M. and Manditseraa, F (2010), Effect of thermal treatment on the phenolic content and antioxidant activity of some vegetables. Asian J. Clin. Nutr, 2:93-100. 
Dasgupta, N. and De, B., 2007, antioxidant activity of some leafy vegetables of India: comparative study. Food che, 101: 471474

Ho, C.-T. (1992). Phenolic compounds in food: An overview. In M.-T. Huang, C.-T. Ho, \& C. Y. Lee (Eds.), ACS symposium series: 507. Phenolic compounds in food and their effects on health II: Antioxidants and cancer prevention (pp. 2-7). Washington, DC: American Chemical Society.

Jacob R.A 1995, The integrated antioxidant system, Nutrition Research, Vol. 15, No. 5, pp. 755-71X.1995

Jeffery, E.H. Brown, A.F., Kurilich, A.C., Keck, A.S., Matusheski, N., Klein, B.P., and Juvik J.A, Variation in content of bioactive components in broccoli, Journal of Food Composition and Analysis 16 (2003) 323-330.

Jimenenz-Monreal, A.M., Gracia-Diz, L., Martinez-Tome, M., Mariscal, $\mathrm{M}$ and Murcia, M. A., 2009, Influence of cooking methods on antioxidant activity of vegetables. J.Food Sci., 74(3): 97-103.

Kahkonen, M. P., Hopia, A. I., Vuorela, H. J., Rauha, J. P., Pihlaja, K., Kujala, T. S., \& Heinonen, M. (1999). Antioxidant activity of plant extracts containing phenolic compounds. Journal Agricultural and Food Chemistry, 47, 3954-3962.

Lindley, M. G. (1998). The impact of food processing on antioxidants in vegetable oils, fruits and vegetables. Trend in Food Science and Techonology, 9, 336-340.

Loliger, J. (1991). The use of antioxidants in foods. In O. I. Aruoma \&B. Halliwell (Eds.), Free radicals and food additives (pp. 121-150). London: Taylor Francis

Namiki, M. (1990). Antioxidant/antimutagens in food. CRC Critical Review Food
Science and Nutrition, 29, 273-300.

Papas, A. M. (1999). Diet and antioxidant status. In A. M. Papas (Ed.), Antioxidant status, diet, nutrition, and health. Boca Raton, London, New York, Washington, DC: CRC Press.

Rahman, K., 2007, Studies on free radicals, antioxidants and co- factors. Clin. interv. Aging., 2(2): 219-236.

Sasipriya, G., Maria, C.L and Siddaraju, P., 2012, Influence of pressure cooking on antioxidant activity of wild and commercial banana unripe fruit and flower. J. Food Science.Tech. 51(10):2517-2525.

Sreeramulu, D., Reddy, C.V.K, Chuhan, A., Balakrishna, N and Raghunath M., 2013, Natural antioxidant activity of commonly consumed plant foods in India: effect of domestic processing. Oxid. Med. Cellular Longev, 2013: Article ID 36479, 12 pages.

Turkmen, N., Sari, F and Velioglu, Y.S., 2005, The effect of cooking methods on total phenolics and antioxidant activity of selected green vegetables. Food chem., 93:713-718.

Velioglu, Y. S., Mazza, G., Gao, L., \& Oomah, B. D. (1998). Antioxidant activity and total phenolics in selected fruits, vegetables, and grain products. Journal of Agricultural and Food Chemistry, 46, 4113-4117.

Wang, H., Cao, G and Prio, R.L., 1996, Total antioxidant capacity of fruits. J. Agric. Food chem.., 44:701-705.

Zhang, D and Hamauzu, Y., 2004, Phenolics, ascorbic acid, carotenoids and antioxidant activity of broccoli and their changes during conventional and microwave cooking. Food chem.., 88:503-509.

\section{How to cite this article:}

Geetha, K., Savita Hulamani and Shivaleela, H.B. 2018. Effect of Cooking on Total Antioxidant Activity, Polyphenols and Flavanoid Content in Commonly Consumed Vegetables. Int.J.Curr.Microbiol.App.Sci. 7(02): 1459-1466. doi: https://doi.org/10.20546/ijcmas.2018.702.176 